\title{
Um relato de experiência sobre a introdução da modelagem de processo de negócio para entendimento e validação de requisitos de um sistema de informação para gestão de vertedouro
}

\author{
Lyssa Priscyla Scherer ${ }^{1}$ \\ Rogério Luis Rizzi ${ }^{1}$ \\ Claudia Brandelero Rizzi ${ }^{1}$ \\ Ivonei Freitas da Silva ${ }^{1}$ \\ Pétterson Vinícius Pramiu ${ }^{2}$
}

\begin{abstract}
Resumo: Este artigo apresenta discussões sobre a utilização de Business Process Management Notation (BPMN) para a compreensão da dinâmica de um Sistema de Informações voltado à Gestão de Vertedouros de Usinas Hidrelétricas, que embarca uma metodologia experimental específica para quantificação de desgaste superficial. Como resultado geral do trabalho, o processo de construção dos diagramas utilizando a notação BMPN viabilizou importante discussão entre a equipe de desenvolvedores e especialistas do domínio. Os diagramas contribuíram para validar o documento de requisitos e também o protótipo do Sistema, que estão sendo devidamente atualizados. Destaca-se a importância da aplicação da execução do BPMN que viabilizou a análise dos requisitos elicitados e documentados e também a análise do protótipo implementado, possibilitando identificar requisitos não previstos, incompletos, inconsistentes, ambíguos ou incorretos para o Sistema em questão. Os diagramas contribuem também para facilitar e agilizar a inserção de novos integrantes à equipe de desenvolvedores.
\end{abstract}

Palavras-chave: Gestão de Vertedouro. Processo de Negócio. Sistema de Informação.

\begin{abstract}
This article presents discussions on the use of Business Process Management Notation $(B P M N)$ to understanding the dynamics of an information system aimed at Management of the Spillways, boarding a specific experimental methodology for quantification of surface wear. As a result of the work, the diagrams of the construction process using the BMPN notation enabled important discussion between the team of developers and domain experts. The diagrams contributed to validate the document requirements and also the prototype of the system, being properly updated. The implementation of the BPMN allowed the analysis of the elicited and documented requirements and also the analysis of the implemented prototype, allowing to identify unforeseen, incomplete, inconsistent, ambiguous or incorrect requirements for the System in question. The diagrams also contribute to facilitating and expediting the insertion of new members to the team of developers.
\end{abstract}

Keywords: Business process. Information system. Management of the Spillways.

\footnotetext{
${ }^{1}$ Centro de Ciências Exatas e Tecnológicas - Universidade Estadual do Oeste do Paraná, Cascavel - Paraná - Brasil.

\{lyssa.scherer@gmail.com, rogeriorizzi@hotmail.com, claudia_rizzi@hotmail.com,ifsse3 @gmail.com\}

${ }^{2}$ Instituto de Ciências Matemáticas e de Computação - Universidade de São Paulo, São Carlos - SP - Brasil

\{ppramiu@gmail.com\}
}

http://dx.doi.org/10.5335/rbca.v9i4.6615 


\section{Introdução}

Desgastes de superfícies de concreto, do tipo abrasivo, erosivo ou por cavitação são provocados pela ação de partículas e fluidos, e ocasionam degradação de turbinas, propulsores, bombas hidráulicas e vertedouros de barragens em usinas hidrelétricas, e outros componentes e estruturas, visto que alteram suas propriedades mecânicas e estruturais, colocando em risco a segurança dos usuários e do meio, além de demandar significativos investimentos para recuperá-los [1].

No caso específico de estrutura de grande porte e elevado investimento, como uma usina hidrelétrica, são requeridos estudos especializados à sua conservação, sobretudo naqueles elementos que estão sob constante ação abrasivo-erosiva, como os vertedouros, que são estruturas hidráulicas que liberam os excedentes de água e regulam o nível do reservatório da barragem, evitando seu colapso. Este aspecto é suficiente para motivar o desenvolvimento de metodologias que subsidiem a gestão às ações de acompanhamento e manutenção que devem ser realizadas em vertedouros.

Metodologias à implementação de tais soluções provêm das Engenharias, e incluem aspectos experimentais, numéricos e teóricos. Incluem técnicas para o gerenciamento de pontos amostrais identificados na calha para monitoramento de pontos estratégicos de desgaste; a comparação de imagens obtidas por técnicas de fotogrametria para registro da evolução de desgastes específicos; e a construção de mapas temáticos da distribuição geoespacial da erosão, entre vários outros encaminhamentos.

Da fotogrametria são extraídas informações precisas por meio de fotografias, incluindo a forma, as dimensões e a posição dos objetos nelas contidos. Viabiliza, pois, a produção de uma série temporal de amostras de interesse no âmbito de lajes ou calhas de um vertedouro. É uma abordagem que provê agilidade à coleta e registro dos dados, com grande precisão e baixo custo, além de não requerer nenhuma intervenção física nas estruturas das lajes. As atividades de gerenciamento de pontos amostrais e de construção de mapas seguem as mesmas qualificações, dada suas interdependências e iguais necessidades de gestão de manutenções [2].

A fotogrametria provê imagens reconstruídas visando à inspeção e a comparação de um mesmo local amostral, entre diferentes instâncias de tempo, o que permite o desgaste ocorrido no tempo. Requer que a coleta seja precisa do ponto de vista do georreferenciamento, viabilizando acurada comparação entre ou intraamostral, em diferentes níveis de tempo, requerendo equipamentos de georreferenciamento adequados. Contudo, essa condição diz respeito somente à coleta das informações amostrais e independe do Sistema que realiza as atividades de armazenamento e processamento dos dados e imagens [3], mas este deve incorporar em suas funcionalidades as atividades necessárias.

Esses aspectos foram caracterizados juntamente a um importante centro de estudo de segurança de barragens, durante a realização de estudos sobre efeitos abrasivo-erosivos na superfície de concreto de vertedouros de barragens de usinas hidrelétricas. Um dos resultados deste trabalho indicou a relevância de conceber um Sistema de Informações Georreferenciado (SIG) à coleta, armazenamento e processamento de dados e imagens georreferenciadas, para prover uma base adequada de informações ao acompanhamento de efeitos abrasivo-erosivos nessas estruturas, assim como das manutenções periodicamente realizadas.

Fornecendo registros precisos às atividades e procedimentos mencionados, um SIG com essas características viabiliza acompanhar estudos experimentais e simulações computacionais ou procedimentos assemelhados, sem o custoso e complexo processo de coleta de dados físicos que, algumas vezes, são inviáveis por envolverem ensaios destrutivos ou por carecerem de padrão de referência para mensurar efetivamente o desgaste da estrutura ou componente.

Previamente à especificação do SIG de interesse, realizou-se uma revisão bibliográfica que indicou a inexistência de um Sistema de Informações à gestão e tomada de decisão de vertedouros de usinas hidrelétricas embasado em metodologias e estudos com suporte formal e experimental, como o apresentado neste trabalho. A revisão bibliográfica indicou a existência de Sistemas com alguns pontos de intersecção a ele.

Há Sistemas de gerenciamento de segurança das usinas, quanto ao controle de instrumentos e a prevenção de erros operacionais, quando do excesso de chuvas. Hysenaj apresenta um SIG que auxilia na tomada de decisões para controle de enchentes na cidade de Shkodër, Albânia. Pode-se acompanhar o volume 
de chuvas, salvar dados sobre enchentes ocorridas, realizar mapas de enchentes anteriores e outras informações que, em conjunto, contribuem para prever regiões de risco por enchentes [4]. Já o sistema BC hydro, [5], identifica situações que podem ocorrer em uma hidrelétrica, como as decorrentes de grande volume de chuvas, ou de catástrofes naturais, ou erros humanos às operações. Pelas informações obtidas da documentação disponível do BC hydro, entende-se que o Sistema indica métodos de prevenção e controle para cada irregularidade encontrada.

Há Sistemas específicos para acompanhamento de desgastes em pavimentos como [6] e [7]. Outro trabalho é o apresentado em [8], que visa o estudo do desgaste de concretos utilizados em usinas. Nele foram feitos experimentos com quatro tipos de concreto, submetendo-os a jatos d'água, após sendo utilizada tecnologia de scan 3D para calcular a perda da massa do material. Essa atividade se assemelha à determinada modelagem experimental e matemática realizada no âmbito deste projeto, e que compõe a metodologia embarcada no Sistema.

O protótipo do Sistema apresentado neste trabalho, designado Sistema de Informação para Gestão de Vertedouro (SIGVERTE) de usinas hidrelétricas, tem como principais funcionalidades: Efetuar o registro histórico de dados quando da construção da usina, por meio da inserção de documentos digitalizados; Gerenciar usuários; Gerenciar calhas; Gerenciar lajes; Gerenciar campanhas/atividades; Gerenciar amostras; Realizar operações de georreferenciamento, considerando a calha do vertedouro, as lajes e as amostras; Realizar operações à visualização dos dados e das amostragens realizadas. Essas funcionalidades, que são tratadas em detalhes em seção específica deste trabalho, foram especificadas em um documento de requisitos e então prototipadas.

Em um determinado momento do desenvolvimento do Sistema, antes da implementação e dos testes, realizou-se a validação dos requisitos e protótipos de telas pelos especialistas no domínio. Concomitantemente, notou-se dificuldades no entendimento dos requisitos e protótipos por parte de novos desenvolvedores que ingressaram no projeto. Assim, para (i) apoiar o trabalho de validação do protótipo, (ii) complementar a documentação do Sistema, (iii) facilitar o entendimento dos requisitos do Sistema e (iv) melhorar a comunicação entre os stakeholders decidiu-se por utilizar a abordagem Business Process Management (BPM) [9]. Essa abordagem contribui para a especificação dos requisitos de sistemas de informação, viabilizando a construção de diagramas conceituais de processos, documentando-os, comunicando e otimizando os processos (requisitos) de um sistema.

O objetivo deste trabalho é apresentar a experiência quanto à adoção da BPM para o entendimento e validação dos requisitos do SIGVERTE. Para o desenvolvimento do modelo de processos foi utilizada a notação Business Process Model and Notation (BPMN) [10], sendo a modelagem baseada nos documentos do sistema e validação realizada por especialistas do domínio.

\section{Gerenciamento de Processos de Negócio (BPM)}

Processo de negócio refere-se ao conjunto de atividades executáveis coordenadamente dentro de um ambiente técnico e organizacional [11]. Devem atender a um objetivo de negócio como, no caso deste trabalho, realizar manutenções em vertedouros. Cadastrar calhas, lajes, pontos amostrais constituem um conjunto de atividades para atender ao objetivo do setor responsável pela manutenção do vertedouro. Modelos de processo de negócio contribuem à especificação de requisitos para sistemas de informação [12], sendo aspecto relevante da metodologia o seu gerenciamento. O Business Process Management (BPM) é uma abordagem que pode ser adotada para tal finalidade, sendo que o ciclo de vida do BPM inclui análise, projeto, implementação, execução e melhoria contínua dos processos da organização [9]. A Figura 1 ilustra o ciclo desta metodologia.

Nesta metodologia, durante a fase de "Estratégia e planejamento do processo", desenvolve-se a estrutura e o direcionamento à gestão contínua dos processos baseados nas metas da organização. Na "Análise dos processos de negócio" as informações referentes aos processos são validadas. Em "Desenho \& Modelagem dos Processos de Negócio" desenvolvem-se os modelos de processo de negócio. Em "Implementação do Processo", o modelo de processo de negócio pode ser automatizado por meio de um sistema computacional, inclusive este é um dos objetivos de BPM, ou seja, contribuir para que ações humanas sejam automatizadas. A etapa de "Controle \& Monitoração do Processo" avalia o desempenho do processo. O "Refinamento do Processo" busca 
aprimorar o processo de negócio e está associado à sua contínua melhoria e otimização. Embora, todas as etapas do ciclo do BPM sejam relevantes, este trabalho direciona seu foco para a etapa de "Desenho \& Modelagem dos Processos de Negócio".

Figura 1: Ciclo de vida do BPM (adaptado de [9]).

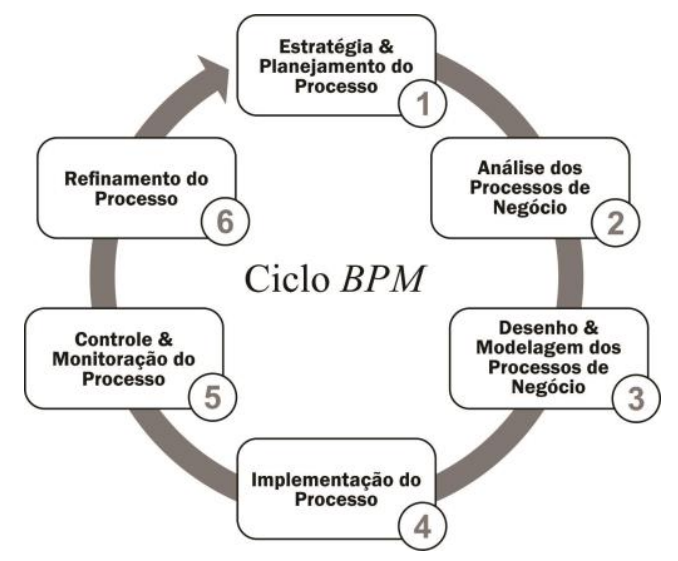

\subsection{Desenho \& Modelagem dos Processos de Negócio}

O desenho e modelagem dos processos de negócio é uma abstração simplificada da estrutura do processo que facilita a comunicação entre stakeholders. Descreve as atividades dentro da organização e como elas se relacionam e interagem com os recursos do negócio, visando alcançar o objetivo do processo [13].

A modelagem é estabelecida como instrumento para construir o diagrama conceitual de processos, documentando, comunicando e otimizando os processos em sistemas de informação [14], [15], [16]. A atividade de modelar processos de negócio inclui a elicitação de atividades e informações inerentes a partir dos stakeholders, para posterior documentação em uma notação específica. Dentre as notações, destaca-se a Business Process Model and Notation (BPMN) é:

“...uma notação gráfica para especificar processos de negócio em um diagrama. BPMN dá suporte ao BPM através de uma notação que é completa para os usuários de negócio e ainda representa semântica de processos complexos para usuários técnicos" [10].

Dentre os diagramas que BPMN oferece, o de processos apresenta as atividades e eventos para compreensão do fluxo do processo. Este trabalho foca na concepção deste diagrama, pois a equipe de desenvolvimento do SIGVERTE necessitou construi-lo para melhor compreender as atividades previamente especificadas em um documento textual inicial e estruturadas em um protótipo computacional, que precisava ser validado. A Tabela 1 apresenta os principais elementos do BPMN utilizados neste trabalho.

Tabela 1: Elementos do BPMN utilizados e seus significados.

\begin{tabular}{|c|c|c|c}
\hline Elemento & Significado & Elemento & Significado \\
\hline & Inicio do Processo & & Fim do Processo \\
\hline & Tarefa/Atividade & & Sub-tarefa \\
\hline$\checkmark$ & Decisão & & Decisão Paralela \\
\hline
\end{tabular}




\subsection{Modelagem de Processos e Requisitos de Sistemas de Informação}

O estabelecimento da modelagem de processos de negócio é uma importante etapa do processo de desenvolvimento de sistemas de informação [9], e o BPMN tem fomentado a comunicação entre engenheiros de sistemas e especialistas de domínio, e melhorado semanticamente a representação do domínio [16]. Durante o processo de desenvolvimento de sistemas de informação, a engenharia de requisitos é fundamental para identificar os requisitos dos sistemas que deverão ser implementados computacionalmente. A modelagem de processos de negócio e a modelagem de requisitos de sistemas de informação são atividades iniciais à construção do software.

Cada atividade de modelagem tem seu objetivo e seu contexto. $\mathrm{O}$ analista de negócio modela os processos de negócio visando melhorá-los, e o analista de requisitos, modela os requisitos do sistema de informação que deve desenvolver. Diversos trabalhos exploram a relação entre essas duas etapas de modelagem. Silva, [17], apresenta uma revisão sistemática da especificação de casos de uso a partir de modelos de processos de negócio. Essa revisão sistemática analisou 13 estudos primários. Esses estudos apresentavam abordagens, automatizadas ou semiautomáticas, que mapeavam casos de uso [18], uma técnica para especificação de requisitos, a partir dos elementos dos modelos de processos de negócio.

E assim como casos de uso contribuem para especificar e validar requisitos de sistemas de informação, outras técnicas ou estratégias também apoiam a especificação e validação. A prototipagem dos requisitos, por exemplo, provê um mecanismo para que usuários do sistema possam contribuir à validação dos requisitos mapeados. Outros métodos para entendimento e validação de requisitos foram introduzidos na literatura a exemplo de revisões e inspeções de requisitos. Porém, eles são genéricos, pois são utilizados para diversos tipos de artefatos do processo de software, como é o caso da revisão e inspeção de código-fonte [19]. Em suma, há falta de práticas de validação de requisitos [19]. Testes de software podem apoiar, porém normalmente são realizados quando todos os módulos do sistema estão desenvolvidos e integrados [19], [20].

Como a modelagem de processos de negócio tem uma relevante relação com a engenharia de requisitos, àquela pode contribuir com a especificação e validação destes. Assim para este trabalho, a modelagem de processos de negócio não foi realizada previamente à engenharia de requisitos, sendo os processos modelados posteriormente devido à característica peculiar do trabalho realizado no âmbito do SIGVERTE, que foi a necessidade de validar os requisitos e o protótipo desenvolvido, bem como facilitar a integração de novos membros à equipe de desenvolvedores.

\section{Principais Funcionalidades do SIGVERTE}

Nesta seção são apresentadas as principais funcionalidades do SIGVERTE a partir do protótipo implementado. O objetivo é explicar o funcionamento do Sistema e também ilustrar o protótipo para melhor caracerizar as discussões que são feitas a seguir quanto ao trabalho realizado com o BPM.

Antes, porém, cabe assinalar que a revisão bibliográfica realizada indica que existem sistemas computacionais voltados a gestão de Vertedouros, mas em geral, trata-se de sistemas comerciais cujas definições e especificidades não são disponibilizadas ou detalhadas. A título de ilustração, pode-se citar como exemplo a empresa NovaTerra, que no conjunto de suas soluções, divulga um SIG/Web para gerenciamento e transparência para os 27 programas ambientais da Santo Antônio Energia S.A [21]. Divulga também um SIG/WEB para gestão dos Programas Ambientais do licenciamento da Usina Hidrelétrica de Serra do Facão [22]. Em ambos os casos, apenas as informações mais gerais desses sistemas são informadas.

Com características que se assemelham em alguns aspectos ao SIGVERTE o SSB [23] foi idealizado a partir da necessidade de agilizar e controlar informações sobre a segurança das barragens de FURNAS. Com funcionamento em plataforma Internet, o SSB possui um banco de dados com séries históricas a respeito de leituras, medidas e critérios de críticas, ou seja, de limites de atenção e alerta. Dentre os diversos dados coletados pelos instrumentos instalados na barragem estão deslocamentos, deformações, vazões, temperaturas, percolações de água e pressões internas nas estruturas e nas fundações. Estes dados são complementados com as observações das inspeções visuais realizadas pelos especialistas. Assim, o sistema facilita a tomada de decisão preventiva em casos de ocorrências de anormalidades nas estruturas. Outro software a respeito do qual se 
obteve informações é o BC hydro [24]. Seu objetivo principal é identificar situações não comuns que podem ocorrer em uma hidrelétrica como um grande volume de chuvas, catástrofes naturais, possíveis erros humanos, entre outros. Após a identificação e a avaliação da situação, o BC hydro sugere métodos de prevenção e controle para cada irregularidade encontrada.

Sabe-se também que há Sistemas em utilização em Vertedouros cujas informações são sigilosas. Assim sendo, mesmo identificando software que potencialmente podem ter funcionalidades semelhantes às do SIGVERTE, há dificuldade de acesso aos detalhes de suas especificações, impedindo que se estabeleça comparações e análises.

O SIGVERTE está sendo desenvolvido para atender à demanda relativa à coleta, ao armazenamento e ao processamento de dados georreferenciados e de imagens para o acompanhamento dos efeitos abrasivo-erosivos de vertedouro de usinas hidroelétricas, assim como das manutenções lá realizadas, fornecendo um registro dos procedimentos efetuados [25]. Embora o Sistema possa ser utilizado por usuários com diferentes níveis de acesso, a apresentação aqui realizada é aquela a partir do ponto de vista de quem tem acesso as suas funcionalidades. Assim que o sistema é acessado por meio da internet, o usuário cadastrado tem a visão inicial do SIGVERTE. Para efetuar o cadastro de uma calha, que é um dos pré-requisitos do Sistema, basta teclar sobre Calha (1) e Cadastrar (2), ação que fará o redirecionamento para a Figura 2, que mostra a tela em que a calha é efetivamente cadastrada.

Figura 2: Cadastro de Calha.

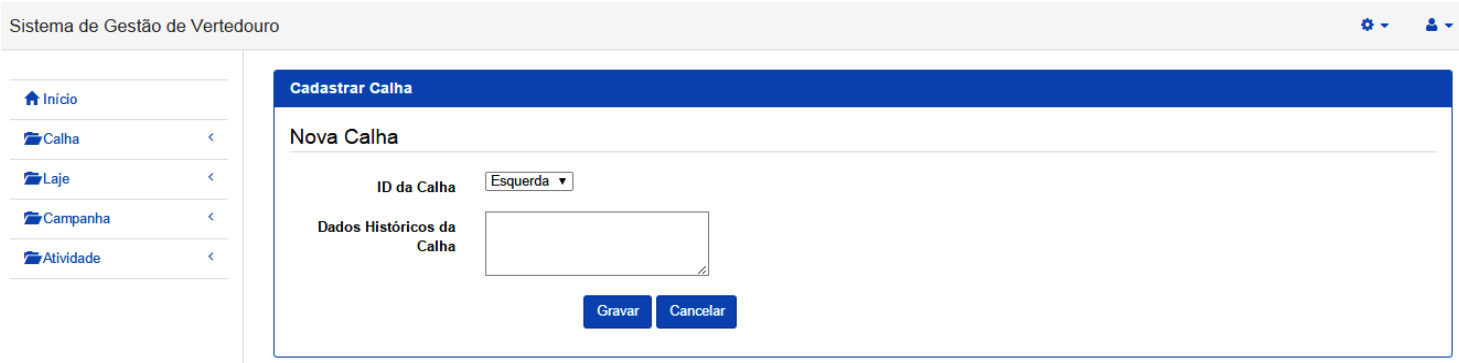

Outro pré-requisito é o cadastro das lajes, que são vinculadas às calhas. Para efetuar o cadastro de uma laje basta clicar sobre Laje e em Cadastrar, para ser redirecionado para a tela ilustrada na Figura 3.

Figura 3: Cadastro de Laje.

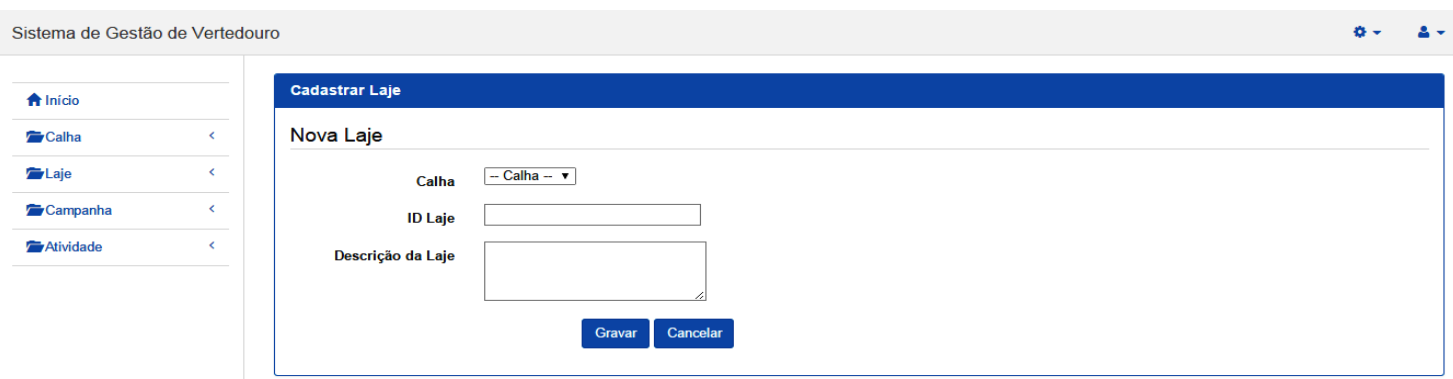

Estão associadas a cada laje, as frentes de concretagem que são as informações sobre como cada laje foi construída e outras pertinentes. O formulário da frente de concretagem, ilustrado na Figura 4 é dividido em cinco abas: Cadastrar (1), Tempo Trabalhado (2), Mão de Obra (3), Máquinas (4) e Croqui (5). Cada aba pode ser preenchida separadamente, sem que o usuário precise cadastrar as informações constantes das outras, bastando clicar sobre o botão Salvar Frente de Concretagem (6). Essas telas não são aqui apresentadas devido à necessidade de objetividade deste trabalho.

Concluídos esses cadastros, é possível definir e iniciar uma campanha. Uma campanha é o conjunto de ações realizadas periodicamente nas lajes, a exemplo de uma visita a uma laje para coleta de fotos via fotogrametria. As campanhas envolvem diversos pontos de cada calha que são definidos previamente com o objetivo de acompanhar sua evolução ao longo de determinado período de tempo. À medida que são obtidas as 
coletas de imagens, podem ser realizadas comparações entre elas, segundo métricas específicas. Após optar pela Campanha, basta clicar em cadastrar que a imagem mostrada na Figura 5 é apresentada.

Figura 4: Cadastro de Frente de Concretagem.

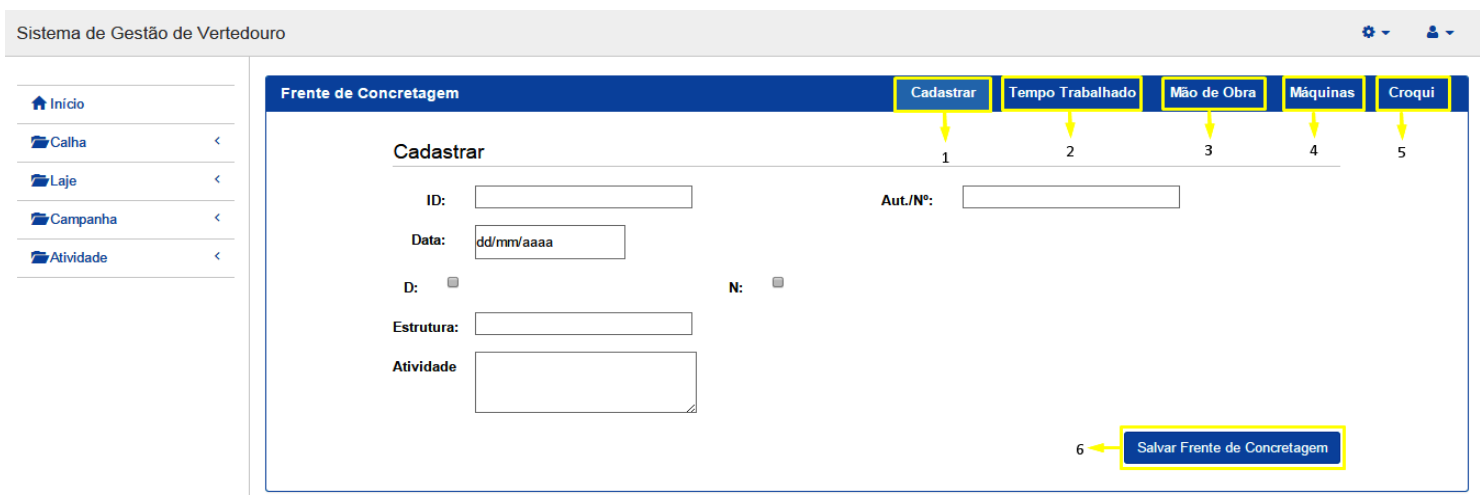

Figura 5: Cadastro de Campanha.

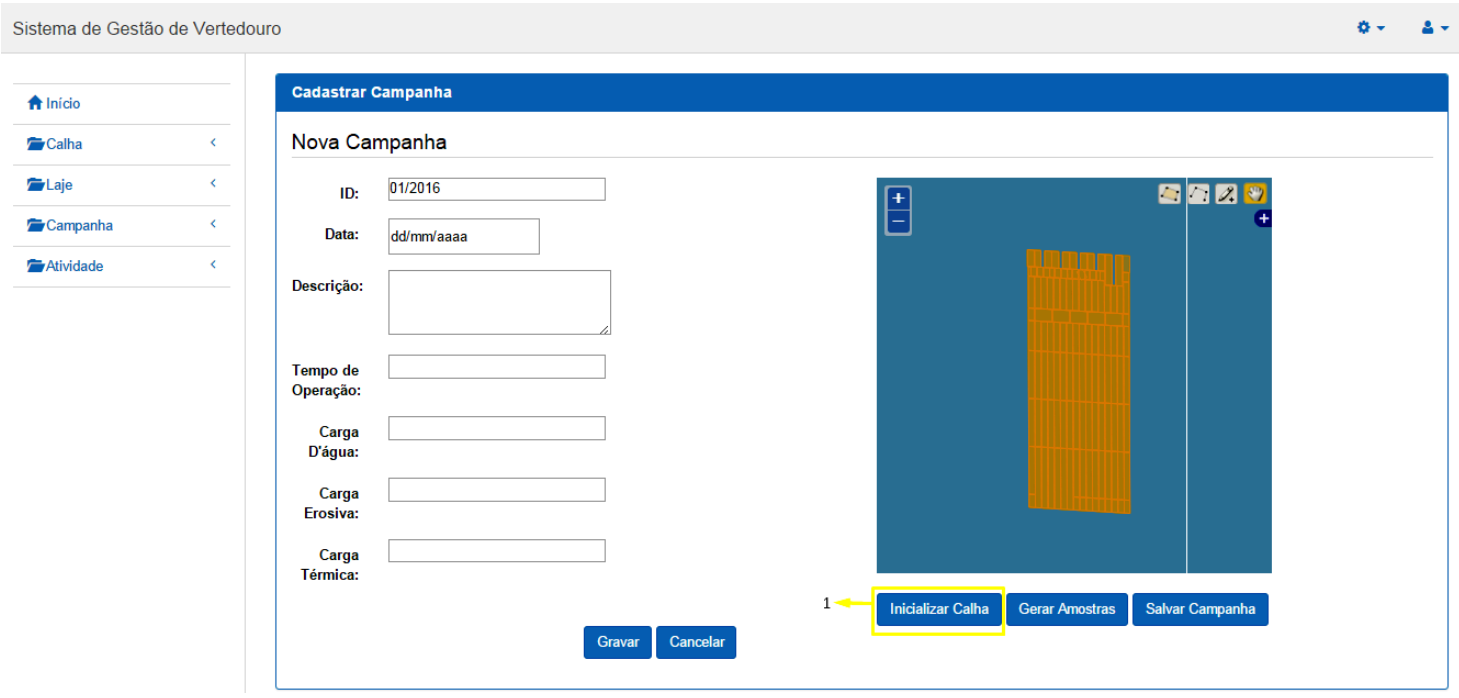

Ao realizar o cadastro de uma campanha, após efetuar o cadastro dos dados, é preciso inicializar a calha. Para isso, o primeiro passo é clicar no botão Inicializar Calha (1) criando um polígono ao redor da calha. A próxima etapa é desenhar um polígono que representará a Campanha na Calha. Para isso basta clicar no botão (1) e com o mouse setar os vértices do mesmo no mapa. Essa funcionalidade gera amostras aleatórias para a campanha dentro do polígono construído.

Entende-se como amostra a coleta de informações de lajes, em diferentes momentos, como campanhas ou atividades, que são utilizadas posteriormente nas métricas que compõem a metodologia que envolve medidas específicas para quantificar os desgastes nas superficies do material, visando avaliar necessidades ou não de manutenção. Uma amostra envolve sua identificação georreferenciada, que é dada no Sistema em termos de um ponto representativo, e o polígono que efetivamente a constitui. Para melhor visualizar o polígono que representa a campanha e as amostras geradas, basta clicar no botão ' + ' no canto superior direito do mapa que será exibido um menu em que podem ser selecionadas as camadas que aparecerão no mapa. Uma camada representa o que é visível no mapa. A Figura 6 destaca o filtro para nova campanha. 
Pode-se fornecer os dados da amostra como ilustra a Figura 7. Posteriormente, pode-se selecionar a amostra, desativar a camada da calha, clicando no botão '+' e desmarcando o campo Calha (1). Essa desativação deve ser feita para melhor visualizar as amostras, facilitando a seleção de uma delas.

Figura 6: Filtrar Camadas para visualizar as Campanhas e Amostras.

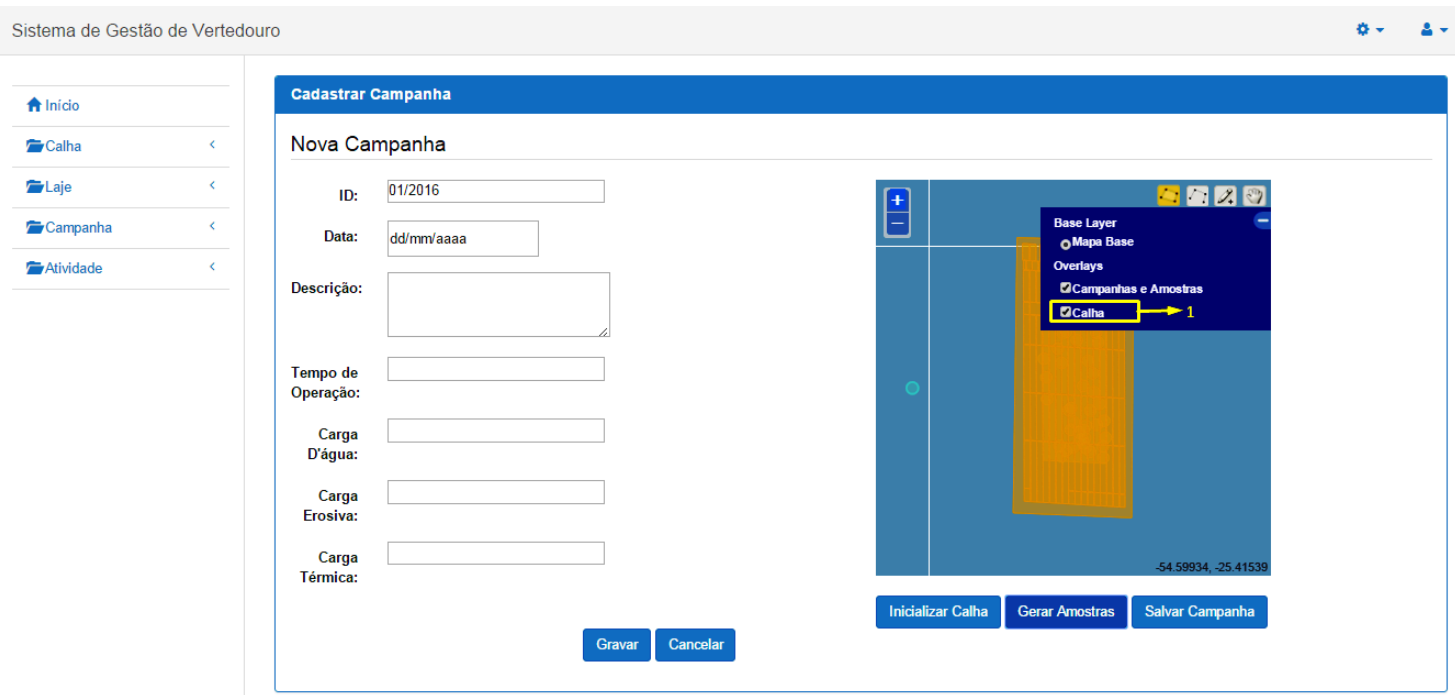

Figura 7: Selecionar Amostra e vincular os dados a ela.

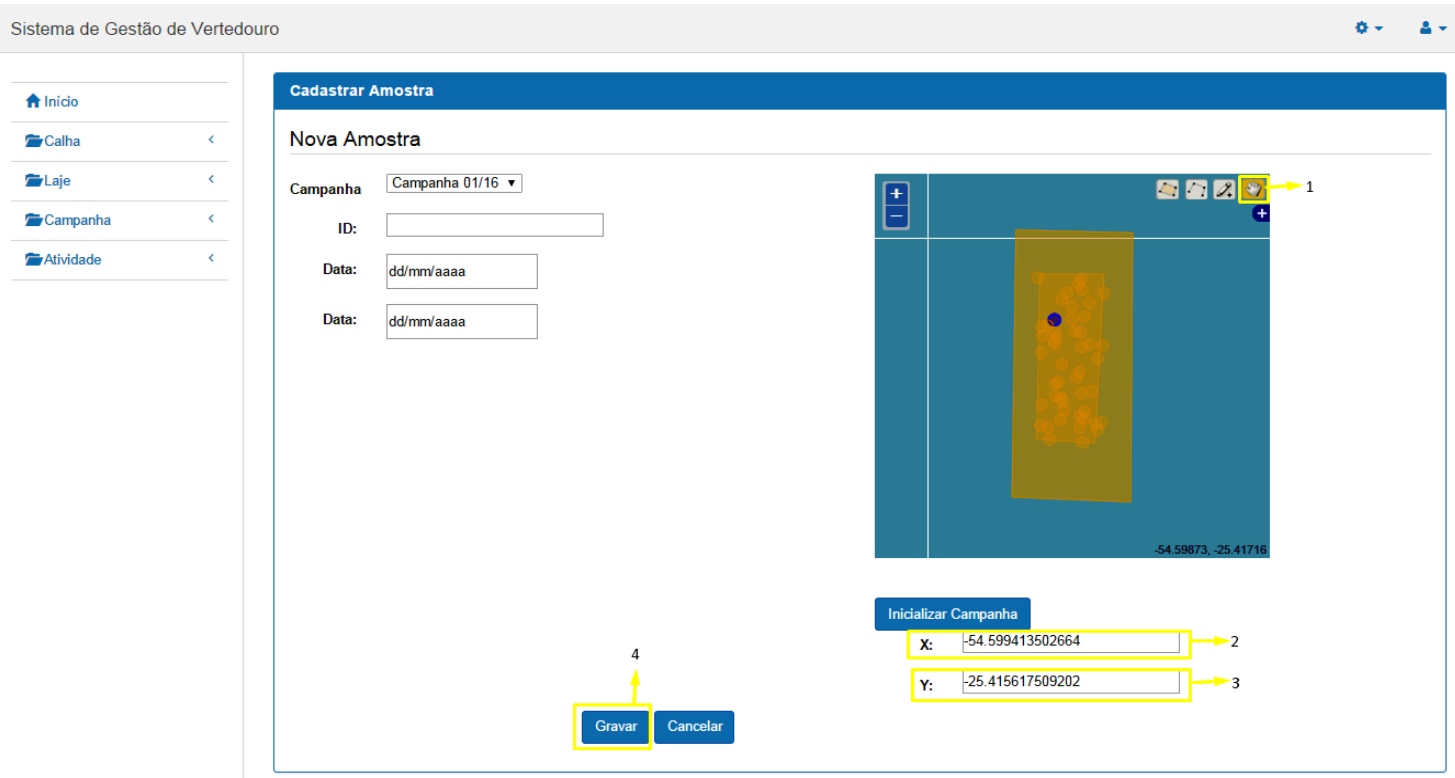

O Sistema SIGVERTE viabiliza o acompanhamento de Atividades, que são as informações sobre as manutenções, monitoramento de pontos estratégicos, sistematização de reparos, entre outras operações realizadas periodicamente na calha em diferentes momentos. Uma Atividade envolve a identificação georreferenciada, o polígono que a constitui e sua imagem. Para efetuar o cadastro de uma atividade, basta clicar sobre Atividade e sobre Cadastrar que será redirecionado para tela ilustrada na Figura 8. 
Como realizado com as Campanhas, nas Atividades também podem ser preenchidas amostras. Para isso, no menu principal deve-se selecionar a Atividade e ativar o botão de seleção, clicar sobre a amostra desenhada que representa a Atividade e os campos das coordenadas latitude (3) e longitude (4) são preenchidos automaticamente. Em seguida, deve-se clicar no botão Salvar Atividade (2) para vincular a amostra desenhada no mapa com a atividade e clicar em Gravar (5) para finalizar o cadastro, como ilustrado na Figura 9.

Figura 8: Cadastrar Atividade.

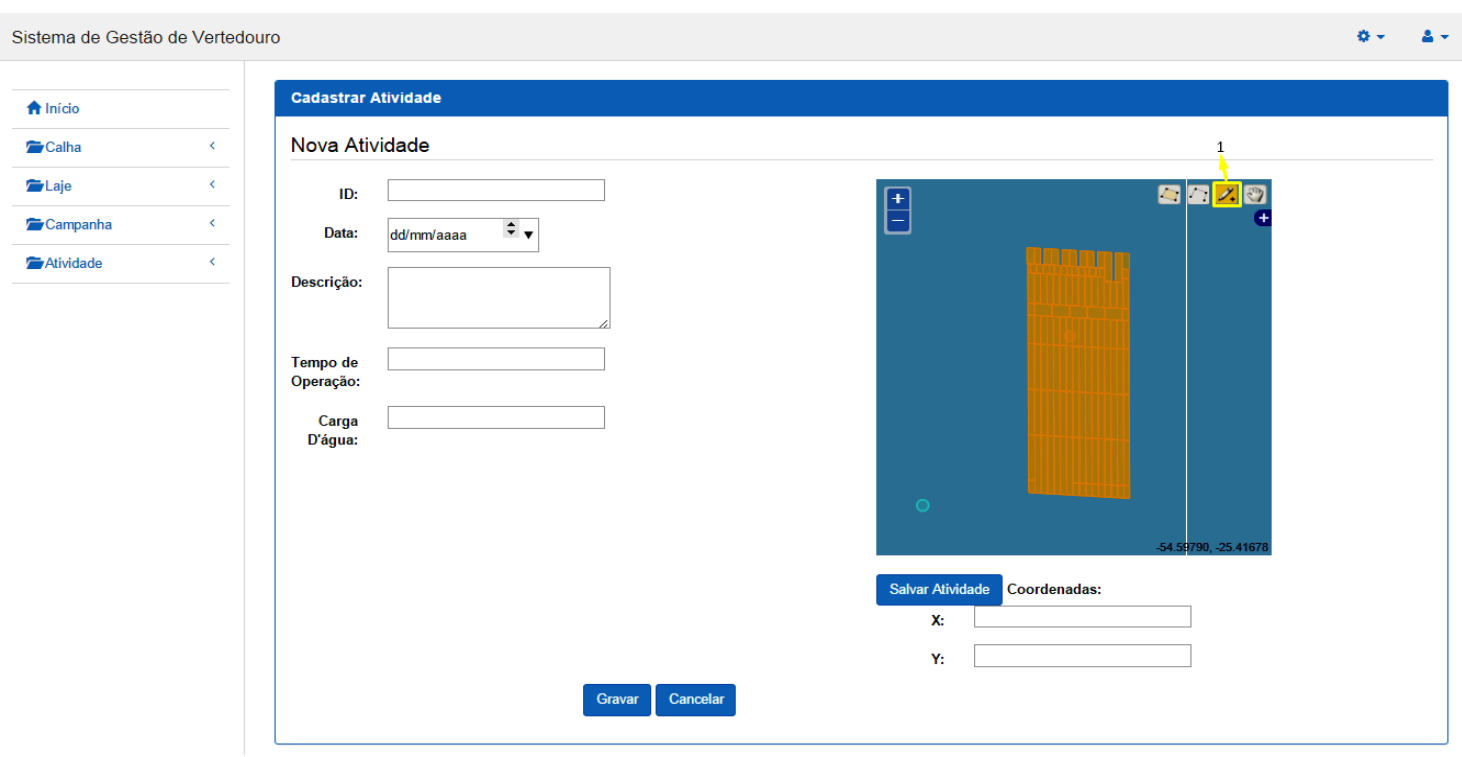

Figura 9: Cadastrar Atividade.

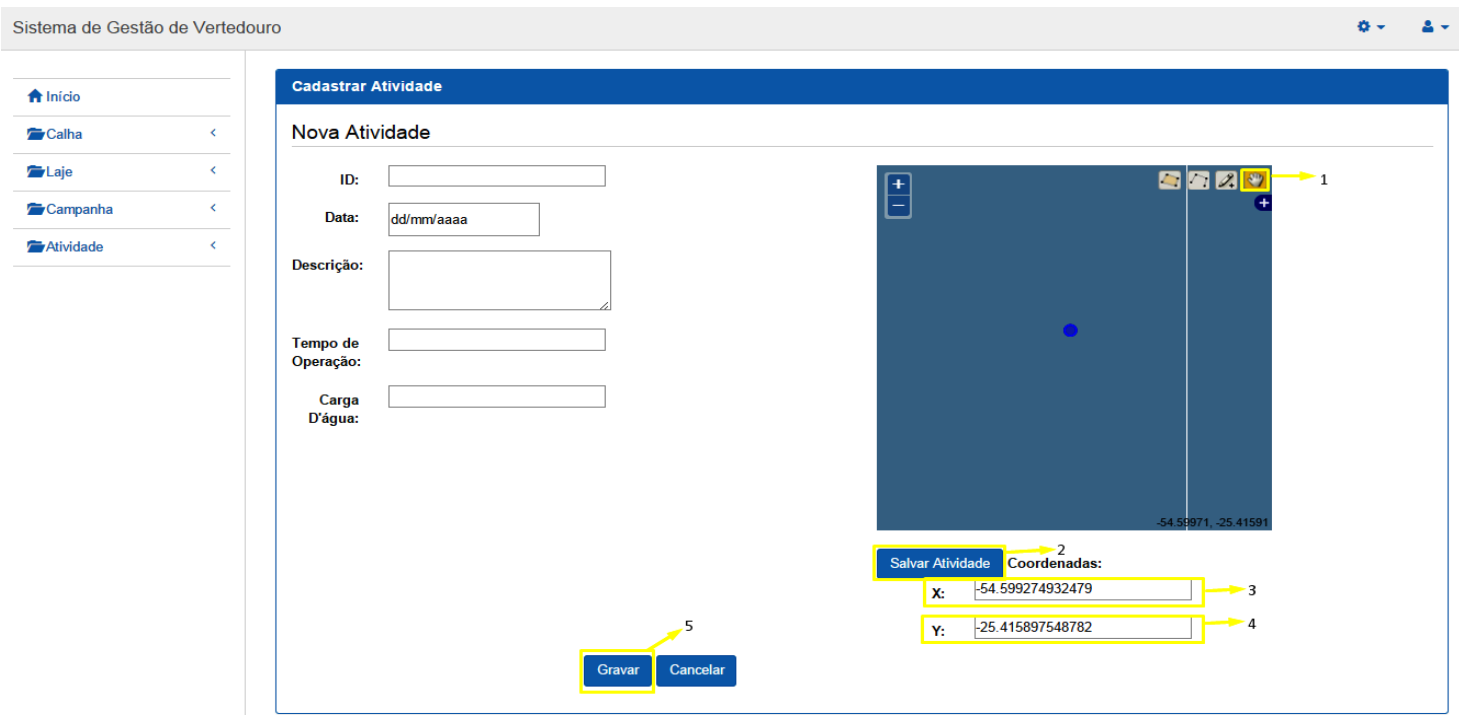

\section{A modelagem dos processos e os Requisitos do SIGVERTE}

As funcionalidades apresentadas na seção anterior são aqui retomadas utilizando a notação BPMN, por meio da ferramenta Bizagi Modeler [26]. Essas funcionalidades foram base para a construção dos diagramas BPMN. Assim, os nomes das atividades foram registrados como estavam especificados no documento inicial ou definidos no protótipo do Sistema SIGVERTE. 
Na adoção do BPM para entendimento e validação dos requisitos e protótipos estiveram envolvidos cinco participantes. Três especialistas no domínio (com conhecimento e participação na elaboração dos requisitos e protótipos) e dois desenvolvedores que modelaram os diagramas BPM, mas que não haviam participado previamente das especificações e prototipagem. Os diagramas da modelagem de processos foram desenhados a partir do protótipo e do documento de requisitos pelo modelador. Após a modelagem, os diagramas foram avaliados por dois especialistas no domínio.

Essa avaliação seguiu um processo simples. Primeiro, uma reunião focal do grupo para validação dos diagramas BPMN; segundo, alterações no modelo foram efetuadas por um modelador dos diagramas; terceiro, validações individuais efetuadas por dois especialistas no domínio; e quarto, outra reunião focal de grupo, com dois especialistas no domínio e um modelador, para validação final dos diagramas BPMN. Durante as reuniões de avaliação dos diagramas nas reuniões focais de grupo, as percepções dos especialistas de domínio sobre os modelos foram capturadas e registradas (são apresentadas na seção 4.1) por um dos desenvolvedores que atuou como pesquisador durante as reuniões, coletando e registrando as informações nas reuniões focais de grupo. Na Figura 10 é apresentado o processo necessário aos requisitos de Calha e Laje.

Figura 10: Diagramas BPMN da Calha e Laje.

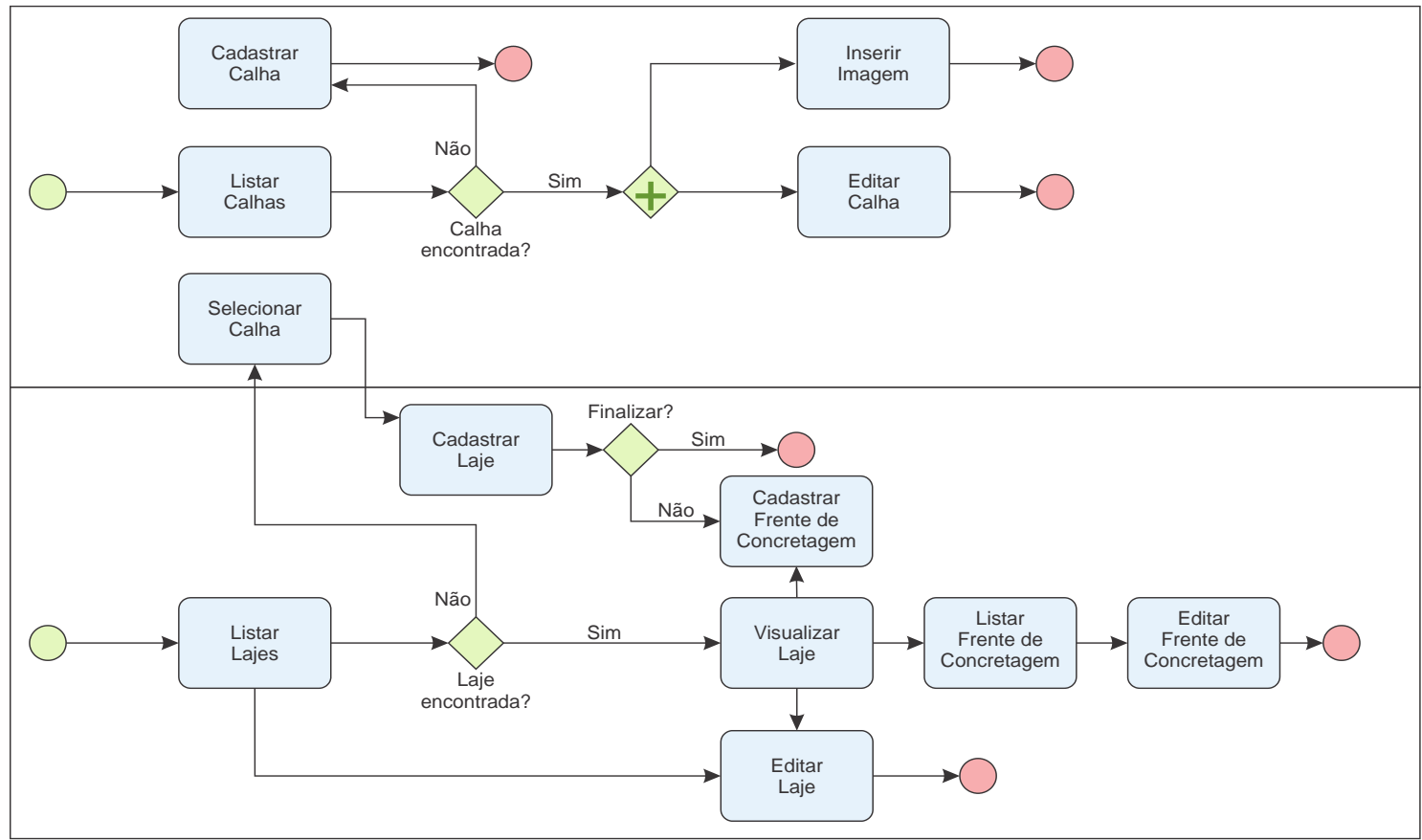

Nos Quadros 1 e 2 são apresentados os requisitos às funcionalidades Gerenciar Calha e Gerenciar Laje que foram documentados. Enquanto os requisitos especificam a funcionalidade, incluindo os elementos que devem conter, o diagrama BPMN ilustra a dinâmica e destaca a relação entre os processos.

\section{Quadro 1: Requisito documentado para Gerenciar Calha.}

[RF-01/Dados] Gerenciar Calha
Prioridade: Alta
Dependência: não há
Descrição: O Sistema deverá suportar o gerenciamento de calhas de vertedouros. Viabilizar a
inserção de sua identificação, seus dados históricos e listar as lajes pertencentes a ela.
Campos:
$\quad$ Calha: E.
$\quad$ Dados históricos: informações históricas sobre a calha, obtidas a partir de um banco de dados
já existente na Usina Hidrelétrica.


Quadro 2: Requisito documentado para Gerenciar Laje.

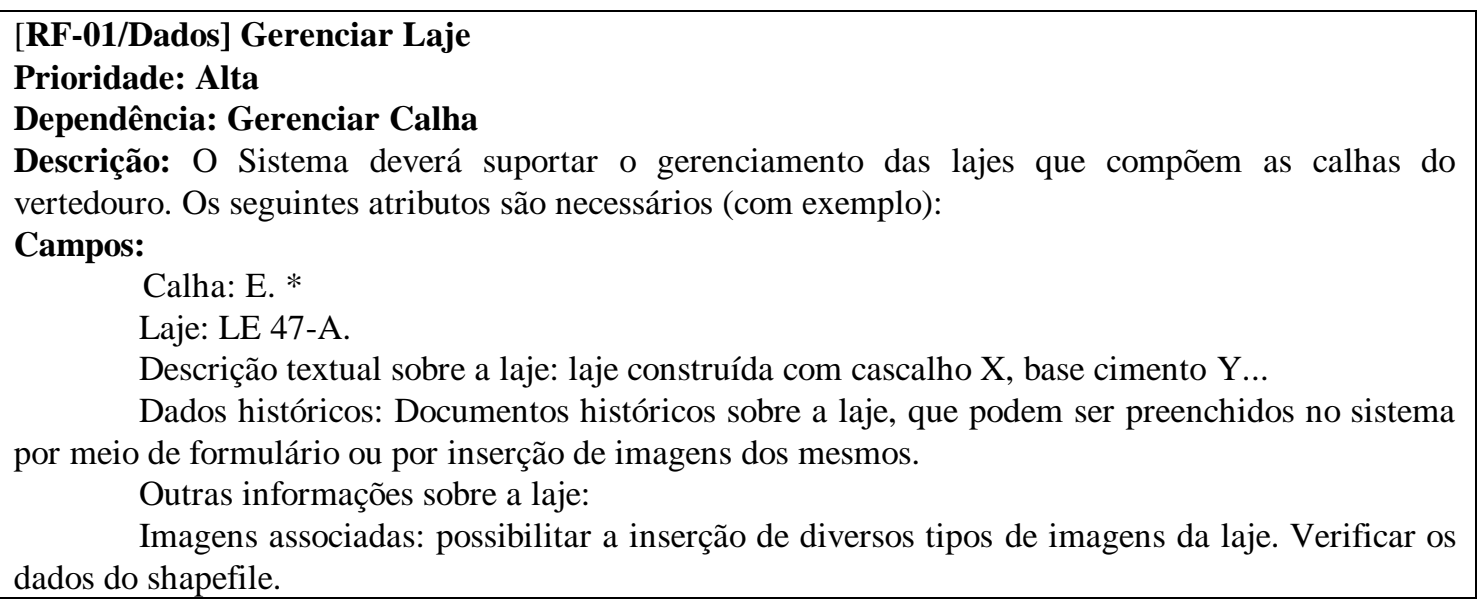

Comparando os Quadros 1 e 2 com o protótipo implementado cujas imagens são mostradas nas Figuras 2 e 3 da seção anterior, pode-se dizer que, embora se trate de um requisito básico e simples, o protótipo não previu a possibilidade de inserir imagens correspondentes às calhas.

Outro aspecto identificado diz respeito ao que consta na versão documentada dos requisitos referentes às lajes mostradas no Quadro 2. As informações relativas a "Outras informações sobre a laje" foram melhor compreendidas quando se teve acesso a um documento impresso, fornecido por técnico vinculado à usina hidrelétrica, que está sendo utilizado como estudo de caso, em que constavam detalhes a respeito da construção das lajes. O protótipo foi então construído considerando os detalhes constantes nesse documento. Não houve a devida correção no documento de requisitos nem mesmo a inclusão de sua imagem no corpo do texto. Porém, o diagrama BPMN correspondente foi capaz de identificar esse aspecto. A Figura 11 ilustra o diagrama BPMN da Campanha e os Quadros 3 e 4 apresentam os requisitos correspondentes documentados.

Figura 11: Diagrama BPMN da Campanha.

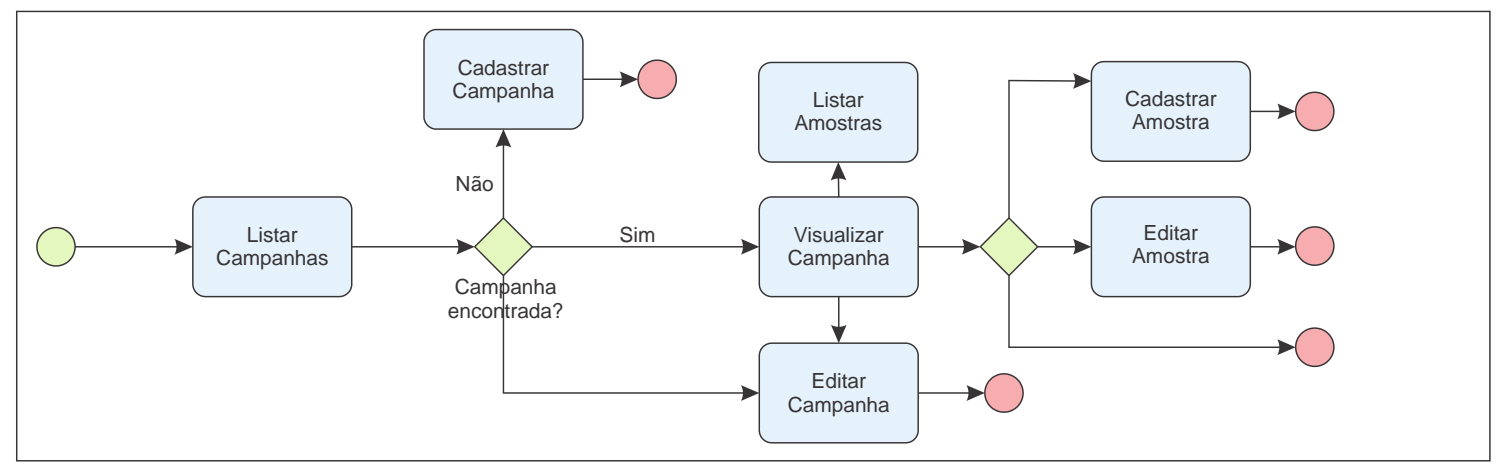

Quadro 3: Requisito documentado para Gerenciar Campanha.

\section{[RF-01/Dados] Gerenciar Campanha}

Prioridade: Alta

Dependência: Gerenciar Calha e Laje

Descrição: O Sistema deverá suportar o gerenciamento das campanhas cujo resultados são coletas feitas em campo em forma de amostra. Os seguintes atributos são necessários (com exemplo):

Campos:

Tipo da Coleta: Campanha

Campanha/Atividade: 02/2015.

Data: 01/10/2015.

Descrição textual: O objetivo desta Campanha é colher amostras referentes a ... 
Identificar a calha onde será feita a coleta: E.

Identificar as lajes que comporão essa coleta: pode haver uma ou mais lajes compondo uma coleta; pode haver várias coletas para cada laje.

Calha Georreferenciada para a seleção das lajes da campanha.

\section{Quadro 4: Requisito documentado para Gerenciar Amostra.}

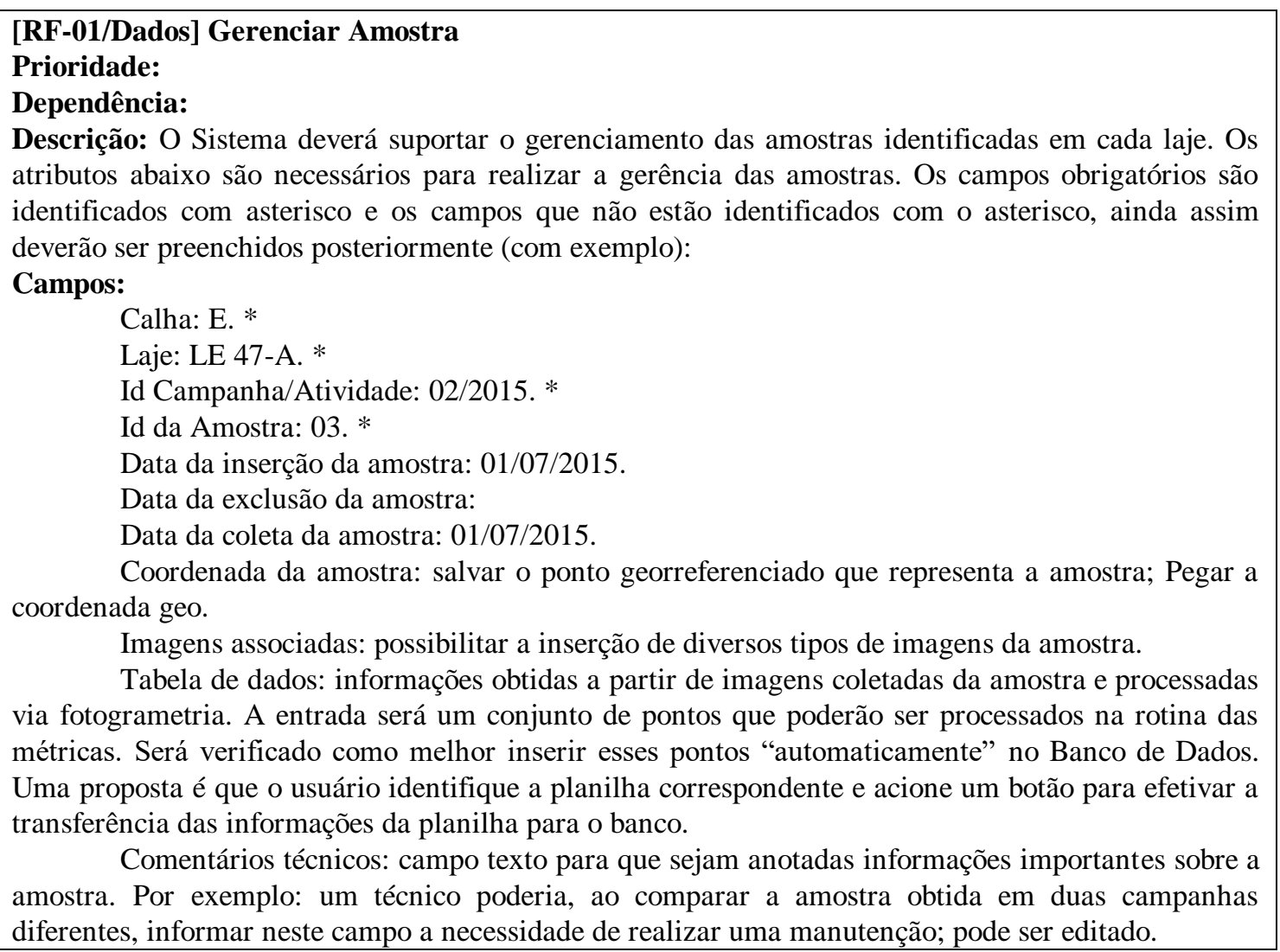

Fez-se uma análise considerando o protótipo ilustrado nas Figuras 5, 6 e 7, o diagrama BPMN da Figura 11 e os requisitos documentados nos Quadros 3 e 4. Com relação aos requisitos do Quadro 4, não foi identificada a prioridade e a dependência do requisito Gerenciar Amostra. Embora o diagrama BPMN ilustre relações entre os requisitos, não detalha os elementos que os compõe, como o faz a documentação de requisitos. Porém, o diagrama BPMN deixa clara a sequência de ações e dependências.

A Figura 7 mostra que no protótipo constam duas datas, sem a devida distinção. No documento de requisitos, são três datas e há distinção entre elas. A Figura 7 também não prevê mecanismo para inserção dos pontos que correspondem à amostra, obtidos via fotogrametria. Também o item "Comentários Técnicos" não foi contemplado no protótipo.

No entanto, detalhes sobre os pontos associados às Campanhas são descritos no documento com sugestões para a construção do protótipo, ao longo de quatro páginas. Ainda assim, a elaboração do protótipo não contemplou essas questões. O diagrama BPMN, por sua vez, identificou o processo, como ilustrado na Figura 12. 
Figura 12: Diagrama BPMN que detalha o Cadastrar Campanha da Figura 11.

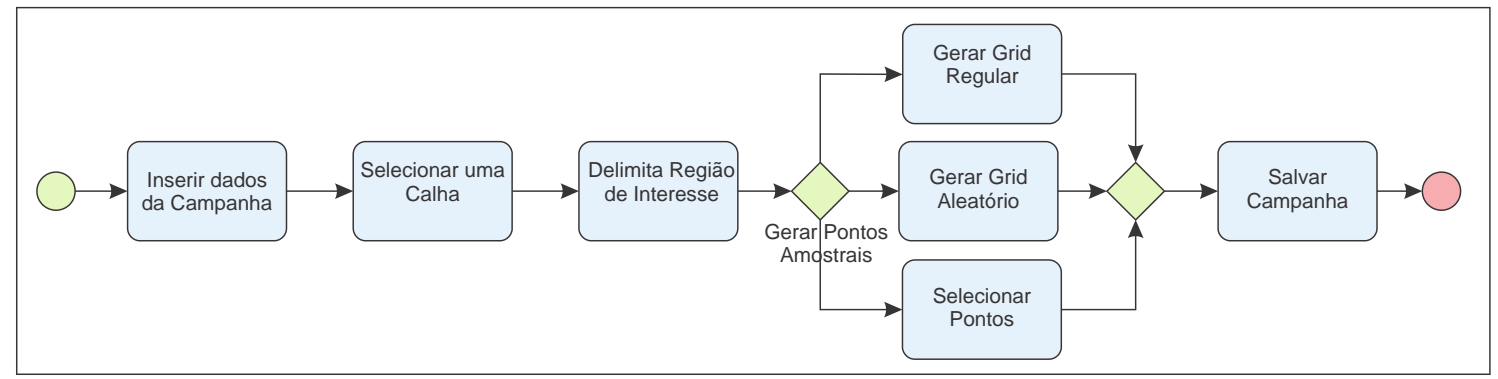

A Figura 13 ilustra o diagrama BPMN da Atividade, o Quadro 5 apresenta os requisitos documentados e as imagens nas Figuras 8 e 9 mostram o protótipo implementado.

Figura 13: Diagrama BPMN da Atividade.

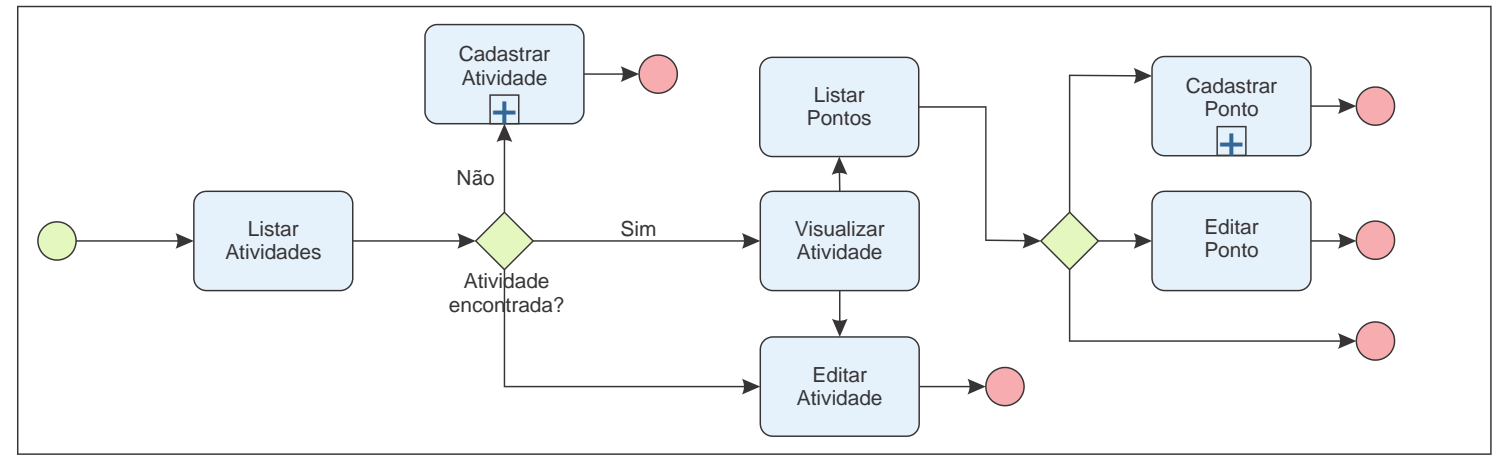

Quadro 5: Requisito documentado para Gerenciar Atividade.

\section{[RF-01/Dados] Gerenciar Atividade}

\section{Prioridade: Alta}

Dependência: Gerenciar Calha e Laje

Descrição: O Sistema deverá suportar o gerenciamento das atividades efetuadas em cada laje. Viabilizar rotina para inserção de imagens. Os seguintes atributos são necessários (com exemplo):

Campos:

Calha: E. *

Laje: 02. *

Id Atividade: 04/2015.

Id da Atividade de Campo: 03.

Data da inserção da Atividade de Campo: 01/07/2015.

Data da coleta da Atividade de Campo: 01/07/2015.

Descrição textual sobre a Atividade de Campo efetuada: eliminação de rachadura com cascalho X, base cimento Y...

Ponto representante: salvar o ponto georreferenciado que representa o local da manutenção.

Polígono representante: salvar o polígono georreferenciado que representa o local da manutenção.

Imagens: imagens da manutenção.

Tabela: informações obtidas a partir de imagens coletadas da manutenção efetuada e processadas via fotogrametria, ou seja, um conjunto de pontos.

Comentários técnicos: campo texto para que sejam anotadas informações importantes sobre a manutenção. Por exemplo: um técnico poderia descrever como foi o processo de manutenção em uma dada rachadura. 
A análise mostra a distinção entre o documentado, o fluxo das operações do Sistema e o respectivo protótipo. Note-se, por exemplo, que no protótipo apresentado nas Figuras 8 e 9 constam dois itens não documentados, o Tempo de Operação e a Carga D'água. Identificou-se que esses elementos foram inseridos provavelmente a partir de um encontro entre o responsável pela prototipação do SIGVERTE e um Engenheiro especialista. Mas não houve a correção da documentação correspondente. A primeira sub-tarefa Cadastrar Atividade, é uma atividade composta de Inserir Dados da Atividade, Selecionar uma Atividade, Selecionar Pontos e Salvar Campanha, e está ilustrada na Figura 14. Os itens não documentados, o Tempo de Operação e a Carga D’água são integrantes de Inserir Dados da Atividade.

Figura 14: Diagrama BPMN da sub-tarefa Cadastrar Atividade.

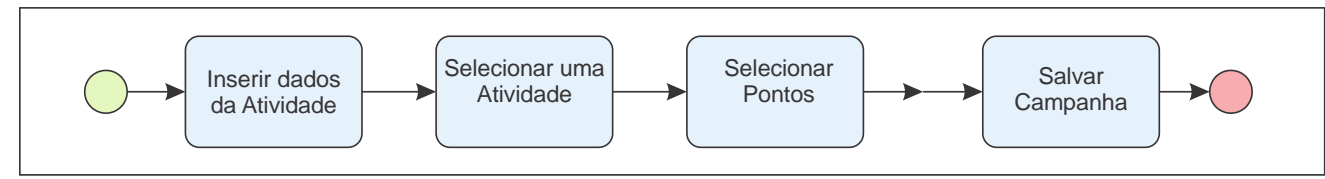

Igualmente, a segunda sub-tarefa Cadastrar Pontos, é uma atividade composta de Inserir Dados do Ponto, Inserir Imagem, Inserir Informações Adicionais, sendo ilustrada na Figura 15.

Figura 15: Diagrama BPMN da sub-tarefa Cadastrar Ponto.

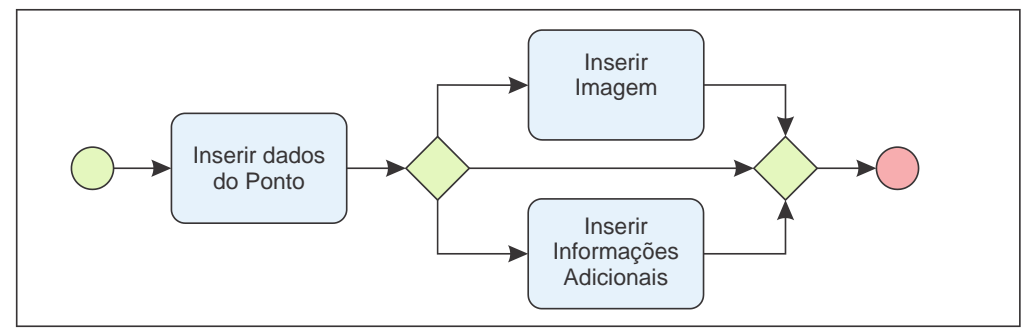

\subsection{Discussão e Lições Aprendidas}

O diagrama de BPMN foi utilizado para validar os requisitos previamente capturados e ratificar o fluxo de execução do Sistema SIGVERTE por meio de seu protótipo funcional. Analisando as percepções relacionadas à validação do documento de requisitos por meio dos diagramas BPMN, observa-se que ambos especialistas do domínio e modeladores identificaram requisitos incompletos, inconsistentes e confusos, bem como, alinharam suas percepções sobre os conceitos presentes no modelo.

Quanto às inconsistências, um exemplo é aquela entre o protótipo e documento de requisitos no gerenciamento de lajes e calha. Essa inconsistência foi identificada pelos especialistas no domínio durante a reunião de avaliação do diagrama BPMN para calha e laje. Como outro exemplo, verificou-se na reunião de avaliação a necessidade de efetuar várias mudanças na semântica dos nomes das atividades. Uma atividade denominada de Gerar Amostra foi renomeada para Gerar Pontos Amostrais. Segundo os especialistas do domínio "essa alteração representa melhor a aleatoriedade do processo".

Como uma lição aprendida, percebeu-se que a modelagem de processos e o documento de requisitos se completam. Como exemplo, na atividade Cadastrar Amostra, novas subatividades (Identificar Rugosidade Superficial do Concreto, Identificação do Nível de Desgaste) foram identificadas ao analisar o diagrama BPMN. Atualmente essas subatividades são realizadas manualmente, mas uma metodologia a elas está sendo desenvolvida e calibrada por engenheiros especialistas no domínio para serem implementadas no Sistema SIGVERTE. Embora necessário, percebe-se que apenas o documento de requisitos não é suficiente para compreender totalmente o fluxo do sistema, dificultando o entendimento de como o Sistema deve ser implementado e funcionar, ficando claro após a diagramação das atividades dos processos. O modelador dos diagramas BPMN também ressaltou a incompletude do documento de requisitos.

Analisando as percepções relacionadas à confirmação do fluxo de execução do Sistema por meio dos diagramas BPMN, observa-se que a reunião de avaliação dos diagramas viabilizou ratificar alguns e retificar outros fluxos de execução do protótipo. Exemplo é a Ficha da Frente de Concretagem. No cadastro da ficha, o usuário deve primeiramente criar a Laje, para em seguida entrar em outro módulo e cadastrar a ficha da Frente 
de Concretagem. Depois de cadastrada, ela é visualizada na mesma página da listagem de Lajes, ilustrada na Figura 4. Porém, durante a modelagem, percebeu-se que o Sistema deveria possibilitar realizar esse cadastro juntamente com o da Laje, e a sua consulta deveria estar dentro da visualização da Laje relacionada, como diagramado na raia Laje do modelo BPMN apresentado na Figura 10. A modelagem de processo propiciou a revisão do fluxo de execução de funcionalidades do protótipo. Esse fato torna-se mais relevante se destacarmos que há falta de visualização do fluxo de processos no documento de requisitos, o que pode conduzir para um protótipo com falhas em termos de fluxo de execução.

\section{Considerações Finais}

Neste trabalho foram apresentadas discussões sobre a utilização de Business Process Management (BPM) para entendimento e validação de requisitos do protótipo do Sistema de Informação Geográfico para gestão de vertedouro de usinas hidrelétricas, denominado SIGVERTE. Dentre suas principais funcionalidades estão a coleta, armazenamento e processamento de dados e imagens georreferenciadas, para prover uma base adequada de informações ao acompanhamento de efeitos abrasivo-erosivos nessas estruturas, assim como das manutenções periodicamente realizadas. Os requisitos do SIGVERTE foram documentados e prototipados [25]. No entanto, da rotatividade da equipe de desenvolvedores, quando um novo integrante ingressava no Projeto, havia dificuldade na compreensão de como o Sistema deveria efetivamente funcionar. Detectou-se que a falta de clareza decorria, principalmente da disponibilidade de documentos e artefatos incompatíveis e sem sincronismo de atualização.

Dada esta problemática, embora não seguindo a lógica natural da proposta do uso do BPM como uma atividade prévia, ou pelo menos paralela à documentação dos requisitos e sua prototipagem, decidiu-se por utilizá-la objetivando entender e validar o documento de requisitos e o protótipo, particularmente no que se referia ao entendimento do processo. Desta decisão decorreram encontros e discussões entre a equipe de desenvolvedores e especialistas de domínio, responsáveis pela sua concepção. Esses encontros se mostraram importantes e viabilizaram o diálogo construtivo, tendo como base a utilização de uma linguagem gráfica compreensível a todos.

Resultou desse processo, que envolveu o desenvolvimento e a melhoria dos diagramas do Sistema utilizando a notação BPMN, o fomento da comunicação e de discussões pertinentes, para uma estruturação de uma percepção geral do Sistema. Esta percepção geral viabilizou a análise tanto das atividades que o documento de requisitos elicitava, quanto as que o protótipo implementava, incluindo àquelas não previstas, incompletas, inconsistentes, ambíguas ou incorretas. Assim, os diagramas BPMN elaborados, além de constituírem atividades de avaliação e validação do documento de requisitos também contribuíram para avaliar e validar o protótipo do SIGVERTE, ações fundamentais ao projeto. Além disso, também contribuem para facilitar a inserção de novos integrantes à equipe de desenvolvedores, com maior qualidade e rapidez.

Como trabalhos em andamento estão sendo realizadas revisões da documentação em que os requisitos são confrontados com o protótipo e o diagrama BPMN correspondente, como exemplificado neste trabalho. Tanto o documento de requisitos quanto o protótipo estão sendo atualizados em conformidade com o identificado em como deve ser a dinâmica geral do Sistema. Outros artefatos, como as imagens do documento de frentes de concretagem e informações sobre Tempo de Operação e a Carga D'água, também estão sendo incluídos e descritos. Após concluída esta etapa, os ajustes ao protótipo serão realizados no sentido de convertêlo em um software funcional.

\section{Agradecimentos}

Ao CNPq e à Fundação Araucária pelo financiamento de bolsa de iniciação científica. À Unioeste pelo apoio logístico. 


\section{Referências}

[1] MOMBER, A. W.; KOVACEVIC, R. "Fundamental investigations on concrete wear by high velocity water flow". Wear, Volume 177 (1), 1994, p. 55 - 62.

[2] SANTOS, P. M. D.; JÚLIO E. N.B.S. "A state-of-the-art review on roughness quantification methods for concrete surfaces". Construction and Building Materials, Volume 38, 2013, p. 912 - 923.

[3] EOS SYSTEMS INC. "Photomodeler Scanner Tutorial".2014. Disponível em: $<$ http://www.photomodeler.com/tutorial-vids/online-tutorials.htm>. Acesso em: 10 jun. 2016.

[4] HYSENAJ, M. "Application Of Geographic Information Systems Towards Flood Management In Shkodër", Albania. Albania, 2012.

[5] BC HYDRO. "Reliability of Flow Control Systems", Disponível em: $<$ http://www.eng.uwo.ca/research/iclr/fids/publications/conferences/FIDS25/12-King.pdf $>$. Acesso em: 12 dez. 2015.

[6] JO, Y.; RYU, S. "Pothole Detection System Using a Black-box Camera Sensors", 15(12), 29316-29331, 2015. Disponível em: <http://doi.org/10.3390/s151129316>. Acesso em: 03 mar. 2016.

[7] PICADO-SANTOS, L., et al. "Pavement management system for Lisbon". Proceedings of the Institution of Civil Engineers. Municipal Engineer. v. 157, Issue ME3, 2004.

[8] HASAN, M. S. "Abrasion on Concrete Surfaces Caused by Hydraulic Loading with Water-Borne Sands". Tese de Doutorado. Concordia University, 2015.

[9] SMITH, H.; FINGAR, P. "Business Process Management: The Third Wave". 1. ed. Heidelberg:MeghanKiffer Press, 2017.

[10] GROUP, O. O. M. "Documents Associated With Business Process Model And Notation (BPMN)". v. 2.0, 2011. Disponível em: <http://www.omg.org/spec/BPMN/2.0>. Acesso em: 20 abr. 2016.

[11] WESKE, M. "Business Process Management: Concepts, Languages, Architectures." 2. ed. Heidelberg: Springer, 2012.

[12] KettingeR, W.; TENG, J.; GUHA, S. "Business Process Change: a Study of Methodologies, Techniques, and Tools". MIS quarterly, 1997, p. 55 - 80.

[13] ERIKSSON, H.E.; PENKER, M. "Business Modeling With UML: Business Patterns at Work". 1. ed. New York, NY, USA: John Wiley Sons Inc., 1998.

[14] FRANK, U. "Conceptual modelling as the core of the information systems discipline - perspectives and epistemological challenges". AMCIS Proceedings, 1999.

[15] WAND, Y.; WEBER, R. "Research Commentary: Information Systems and Conceptual Modelling - A Research Agenda". Information Systems Research, Volume 13(4), 2012, p. 363 - 376.

[16] BRAUN, R.; SCHLIETER, H. "Requirements-based development of BPMN extensions: The case of clinical pathways". In: IEEE $1^{\text {ST }}$ International Workshop on the Interrelations Between Requirements Engineering and Business Process Management (REBPM). Karlskrona: 2014, p. 39 - 44.

[17] SILVA, A. L. B. "Obtendo Casos de Uso a Partir de Modelos de Processos de Negócio: Uma Revisão Sistemática". Trabalho de Conclusão de Curso em Ciência da Computação. Unioeste, 2016.

[18] COCKBORN, A. "Writing Effective Use Cases". 1. ed. Boston, MA, USA: Addison-Wesley Longman Publishing Co., Inc., 2000.

[19] HEINONEN, S.;TANNER, H. "Early validation of requirements in distributed product development: an industrial case study". In Proceedings of the 2010 international conference on On the move to meaningful internet systems (OTM'10), Robert Meersman, Tharam Dillon, and Pilar Herrero (Eds.). Springer-Verlag, Berlin, Heidelberg, 2010, p. 279-288. 
[20] JIANG, L.; EBERLEIN, A.; FAR, B.H. “A case study validation of a knowledge-based approach for the selection of requirements engineering techniques". RE Journal, 2008.

[21] SIG/WEB - UHE Santo Antônio Energia S.A. NovaTerra. Disponível em <http://www.novaterrageo.com.br/portfolio/sig-web-uhe-santo-antonio-energia/>. Acesso em 23: out. 2017.

[22] SIG/WEB - SEFAC - Serra do Facão S.A. NovaTerra. Disponível em <http://www.novaterrageo.com.br/ portfolio/sig-web-sefac-serra-do-facao-sa/>. Acesso em: 23 out. 2017.

[23] SSB Furnas. "Sistema de Segurança de Barragens (SSB)”. Revista Linha Direta no 298 , julho 2003. Disponvel em <http://www.furnas.com.br/arqtrab/ddppg/revistaonline/linhadireta/LD298_mcapa.pdf>. Acesso em: 23 out. 2017.

[24] King L. "Reliability of flow-control Systems". BC Hidro. Disponível em <http://www.eng.uwo.ca/research/iclr/fids/publications/conferences/FIDS25/12-King.pdf>. Acesso em: 23 Out. 2017.

[25] SCHERER, L. P.; SENGER, R.; RIZZI, C. B.; RIZZI, R. L.; PRAMIU, P. V.; SILVA, I. F. “Atividades para especificação, prototipação e avaliação de um sistema de gestão de vertedouro”. Revista Eletrônica Científica Inovação e Tecnologia, v.2, n. 14, p.161-171, 2016.

[26] BIAZIG MODLER. 2016. Disponível em: <http://www.bizagi.com/en/products/bpm-suite/modeler〉. Acesso em: 10 mai. 2016. 